\title{
XLV. The electrical effects produced by the explosion of hydrogen and oxygen
}

\section{C.E. Haselfoot \& P.J. Kirkby}

To cite this article: C.E. Haselfoot \& P.J. Kirkby (1904) XLV. The electrical effects produced by the explosion of hydrogen and oxygen , Philosophical Magazine Series 6, 8:46, 471-481, DOI: 10.1080/14786440409463215

To link to this article: http://dx.doi.org/10.1080/14786440409463215

册 Published online: 15 Apr 2009.

Submit your article to this journal $\sqsubset \pi$

Џ Article views: 4

Q View related articles $\square$

Citing articles: 1 View citing articles $\square$ 


\section{$\left[\begin{array}{ll}471 & 0\end{array}\right.$}

XLV. The Electrical Effects produced by the Explosion of Hydrogen and Oxygen. By C. E. НAsELFoot, late Fellow of Hertford College, and the Rev. P. J. Kinkвy, Fellow of New College, Uxford $*$.

7 THE following experiments were undertaken to investigate 1 the electrical effects which accompany the explosive combination of hydrogen and oxygen ; it having been already shown by preliminary experiments that such effects do exist. The method adopted was to produce an explosion of the mixed gases between two cylinders, of which the inner was a thick wire. On establishing a difference of potential between the wire and the outer cylinder, a flow of electricity to the wire was observed. In order to measure this more accurately, the following apparatus was devised :-

Hydrogen and oxygen were generated by the electrolysis of pure barium hydrate, kindly supplied by Mr. H. B. Baker, in a glass tube A (fig. 1), and were admitted to a vessel B

Fig. 1.

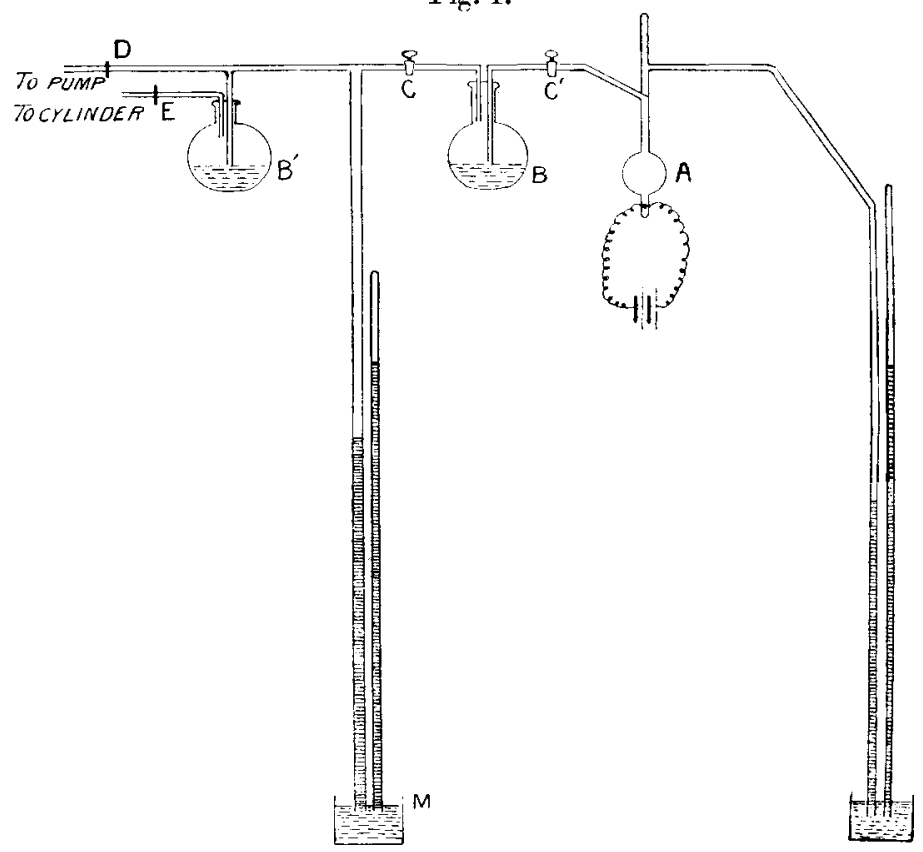

containing phosphorus pentoxide. From this they could be passed through a stopcock $\mathrm{C}$, either to a Fleuss pump through

* Communicated by Prof. J. S. Townsend, F.R.S. 
pressure-tubing, which could be pinched at $\mathrm{D}$, or through a drying vessel $\mathbf{B}^{\prime}$ and a piece of pressure-tubing, which could be pinched at $\mathrm{E}$, into the apparatus represented by fig. 2 .

Fig. 2.

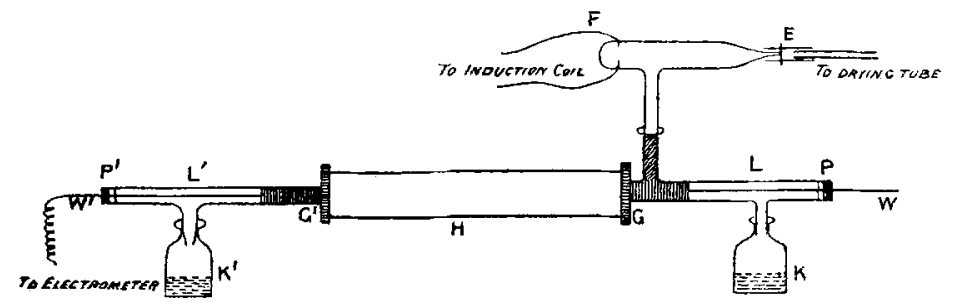

This consisted of an aluminium cylinder $\mathrm{H}, 26.5 \mathrm{~cm}$. long, $41.5 \mathrm{~mm}$. internal diameter, closed by ebonite ends into which brass tubes $G, G^{\prime}$ were fitted. To these were fastened by means of ebonite plugs two glass tubes $L, L$, each of wbich formed a kind of $T$-piece, the lower branches fitting into two removable glass bottles $\mathrm{K}, \mathrm{K}^{\prime}$ containing phosphorus pentoxide. By this means the phosphorus pentoxide could be easily renewed without taking the apparatus to pieces. A brass wire, of $3.25 \mathrm{~mm}$. diameter, was fastened along the common axis of the cylinder and tubes, resting in ebonite plugs $\mathrm{P}, \mathrm{P}^{\prime}$, and was connected to one pair of quadrants of an electrometer. The apparatus was completed by a piece of glass-tubing, fitting into the pressure-tubing $\mathrm{E}$, and fastened by elastic glue into a short brass tube soldered into the tube G. Platinum wires were fused into the glass-tubing at $\mathrm{F}$, and could be connected to the terminals of an induction-coil. Thus the gas could be exploded. By alternately pumping out the apparatus and filling it with dried hydrogen and oxygen the pressure of air in the cylinder could be reduced to a fraction of a millimetre.

The course of an experiment was as follows :-The hydrogen and oxygen to be exploded were admitted to the required pressure, the pinch-cock $\mathrm{E}$ was closed, and the pressure $p_{0}$ inside the cylinder was read; $G$ and ' $G^{\prime}$, dividing the insulations between the cylinder $\mathrm{H}$ and the wire $\mathrm{W}$, were then earthed, and the cylinder was charged to any desired potential by connecting it to one terminal of a battery, the other terminal of which was to earth. The field of force baving been established, the quadrants connected to the wire W, which had previously been earthed, were insulated, and no deflexion of the electrometer was observed. The gases were then exploded and the quantity of electricity thrown on to 
producel by the Fiplosion of Hydrogen and Oxygen.

the wire was determined by an observation of the electrometer in the way fully described below. Finally the pincheock $E$ was opened and the pressure read on the manometer. From these observations the fall of pressure caused by the explosion is easily deduced, when the ratio of the volume, $\mathrm{V}$, of the apparatus of fig. 2 , in which the explosion takes place, to the volume, $v$, of the apparatus in fig. 1 between the stopcocks C, D, and $\mathrm{E}$ is known. This ratio was determined as 1.4 in the apparatus used.

It was found in the preliminary experiments that the effect of the explosions was to break down the insulations, owing, no doubt, to water-vapour being thrown on to the insulators. It was to obviate this that the bottles $K, K^{\prime}$ were designed, the phosphorus pentoxide in which served the double purpose of protecting the insulators and of absorbing the watervapour. $P^{\prime}, P^{\prime}$ were further protected by small circular ebonite shields placed on the wire, as shown in the figure, close to, but not touching, the glass tubes. These shields, in addition to intercepting the water-vapour, screened the insulators from fragments of phosphorus pentoxide, which were in some eases blown into the cylinder by the explosion.

The preliminary experiments had led us to believe that the electricity produced was a small charge, which could be best measured by the deflexions of an electrometer connected with a condenser of small capacity; but with the improved apparatus it was found that a condenser of the order of a microlarad was required. The following was the method adopted for measuring the quantity of electricity generated.

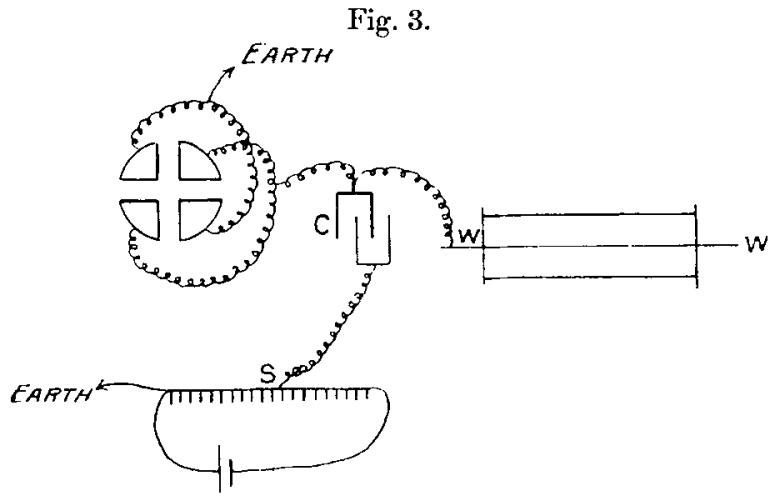

The quadrants in metallic communication with the wire $\mathrm{W}$ were connected with one terminal of a condenser ( $t$, the other terminal of which was connected with the slider of a bigh. resistance potentiometer, as shown in fig. 3. The electrodes 


\section{Messrs. Haselfoot and Kirkby : Electrical Effects}

of the latter were attached by wires to the poles of a battery of two volt accumulators, one of the poles, of course, being put to earth. Immediately before the explosion the quadrants were insulated, and on the explosion taking place the electrometerneedle was brought back to its zero by moving the slider $\mathrm{S}$ of the potentiometer from the point of zero potential along the potentiometer-scale. When thr̈s has been done the potential of one terminal of the condenser is zero, of the other, V, the potential shown by the potentiometer. The charge on the condenser is therefore $\mathrm{CV}$, where $\mathrm{C}$ is the capacity of the condenser, and this is the quantity of electricity thrown on to the wire $W$. This method greatly extended the range of the electrometer, which was of the Dolezalek pattern, in measuring quantity. Moreover, by thus employing a null method the leak of electricity on the electrometer was rendered negligible. A slight leak was observed in the condenser, but it was possible to read the potential before the loss due to this canse had time to become appreciable. It was verified that no effect was produced on the electrometer, either by the spark when no explosion took place, or by an explosion when the wire and cylinder were at the same potential. It follows, therefore, that the charge acquired by the wire is due to the action of the electric field in collecting the ions generated by the explosion. Under the action of the field, if the cylinder is kept at a positive potential, the positive ions are driven to the wire, the negative to the cylinder, and the wire acquires a positive charge. If the cylinder is kept at a negative potential, the reverse effect takes place; but the phenomenon might be further complicated owing to the generation of ions by collision, as the negative ions pass through the intense field of force around the wire. For this reason the cylinder was kept at a positive potential.

It was found that the explosion would not take place if the pressure of the combined gases was much below $80 \mathrm{~mm}$., and that explosions of the gases at a pressure above $100 \mathrm{~mm}$. endangered the air-tight joints of the apparatus. The experiments were therefore confined to this range of pressures.

The results are shown in the following table, where:-

$\mu=$ the pressure in $\mathrm{mm}$. of the mixed gases before the explosion,

$p^{\prime}=$ the fall of pressure in $\mathrm{mm}$. resulting from the explosion and the absorption of the watervapour formed by it,

$1^{\prime \prime}=$ the pressure in mm. of the unexploded gas (viz. $\left.p^{\prime \prime}=p-p^{\prime}\right)$, 
produced by the Explosion of Hydrogen and Oxygen. 475

$\mathrm{Q}=$ the quantity of electricity in micro-coulombs thrown on to the wire $W$,

$q=$ the quantity in micro-coulombs per $\mathrm{mm}$. fall of pressure $\left(=\mathrm{Q} / p^{\prime}\right)$,

$\mathrm{V}=$ The (positive) potential in volts of the outer cylinder, that of the wire $W$ being initially zero.

TABLE I.

\begin{tabular}{|c|c|c|c|c|c|}
\hline$p$ & $p^{\prime}$ & $p^{\prime \prime}$ & v. & Q. & $q$. \\
\hline $74 \cdot 5$ & 68.5 & 6 & -41 & 1.84 & .027 \\
\hline 87 & 81 & 6 & 41 & 1.7 & 021 \\
\hline 77 & 72 & 5 & 124 & 1.45 & .02 \\
\hline 78.5 & 63 & $15 \cdot 5$ & 206 & .46 & $\cdot 0073$ \\
\hline 81 & 74 & 7 & 206 & 5 & .0068 \\
\hline 80 & 60 & 20 & 41 & .24 & $\cdot 004$ \\
\hline 96 & 90 & 6 & 41 & .45 & $\cdot 005$ \\
\hline 103 & 100 & 3 & 82 & .82 & $\cdot 0082$ \\
\hline $87 \cdot 5$ & 82 & 55 & 206 & 587 & .0072 \\
\hline $79 \cdot 5$ & $59 \cdot 5$ & 20 & 206 & .331 & $\cdot 0039$ \\
\hline
\end{tabular}

The amount of air present was 41. $\mathrm{mm}$. in the last experi-ment; in the others it was less than $1 \mathrm{~mm}$.

The capacity of the condenser used varied from one-fifth of a microfarad to a microfarad, the potential to which it was raised lay between a quarter of a volt and two volts. The charge observed was therefore much larger than had been anticipated from the preliminary experiments, ranging, as it did, from a quarter of a microcoulomb to nearly two microcoulombs, and the electrometer was accordingly discarded in favour of a ballistic d'Arsonval galvanometer. To measure the charge the wire $W$ was connected with one terminal of the galvanometer, the other terminal being put to earth. Thus the whole charge passed through the galvanometer and was measured ballistically. The following are the results, in which Table II. refers to a low-resistance galvanometer,

Table II.

\begin{tabular}{|c|c|c|c|c|c|c|}
\hline$p$. & $p^{\prime}$. & $p^{\prime \prime}$ & $\pi$. & V. & Q. & $q \cdot$ \\
\hline 86 & 79 & 7 & 7 & 240 & $11 \cdot 4$ & $\cdot 144$ \\
\cline { 1 - 2 } 8.5 & 82 & $4 \cdot 5$ & 5 & 240 & $4 \cdot 4$ & $\cdot 054$ \\
88 & 84 & 4 & 7 & 240 & $3 \cdot 1$ & 037 \\
\hline
\end{tabular}


TABLE III.

\begin{tabular}{|c|c|c|c|c|c|c|}
\hline$p$. & $p^{\prime}$. & $p^{\prime \prime}$. & $\pi$. & r. & Q. & $q$. \\
\hline 86 & 83 & 3 & 2 & 83 & $3 \cdot 2$ & .038 \\
\hline 845 & 80 & 45 & $=5$ & 83 & 61 & .0076 \\
\hline 83.5 & 76 & 75 & $2 \cdot 2$ & 83 & .78 & .0103 \\
\hline $85 \%$ & 78 & $7 \cdot 5$ & 1 & 83 & .53 & .0068 \\
\hline 85 & $82 \cdot 5$ & 35 & 1 & 83 & $I \cdot 14$ & .014 \\
\hline 85 & 80 & 5 & 006 & 83 & $1 \cdot 11$ & 014 \\
\hline 91 & $78 \cdot 5$ & 125 & 9 & 81 & .97 & 012 \\
\hline 91 & 75 & 16 & 8 & 81 & 7 & .093 \\
\hline 90 & 73 & 17 & 17 & 81 & $2 \cdot 42$ & .033 \\
\hline 92 & 60 & 23 & 17 & 81 & 7 & 01 \\
\hline 91 & 72 & 19 & & 240 & .94 & .013 \\
\hline 100 & 88.5 & 11.5 & $\cdot 06$ & 240 & .61 & .0069 \\
\hline 100 & 825 & 17.5 & 16 & 240 & .88 & .011 \\
\hline 94 & 71.5 & 225 & 29 & 240 & $2 \cdot 3$ & .032 \\
\hline 94 & 65 & 20 & 44 & 240 & .93 & .014 \\
\hline
\end{tabular}

Table III. to a more sensitive one. In the former case it was found that a microcoulomb produced a throw of 6.5 divisions, in the latter a throw of 36 divisions. The notation is as before, and $\pi$ is the pressure of the air, so that the initial pressure is $p+\pi$.

Five other observations were taken, but they are not reproduced, as the deflexions ranged from only 5 to $8 \frac{1}{2}$ divisions on the galvanometer-scale, and the percentage error in reading may have been considerable. They are, however, of some interest, since they are fairly consistent, and they give values of $q$ whose mean is $\cdot 012$. For comparison with previons values this may be taken as 01 , as explained later.

Ten other observations were taken. In three of these the deflexion was very small and not more than $\cdot 04 \mathrm{~mm}$. of air was present; they give values of $q$ whose mean is $\cdot 0027$. In five others the amount of air was small, probabiy not more than a millimetre. They give a mean value of $q$ equal to -0057. The remaining two were made with $25 \mathrm{~mm}$. and $26 \mathrm{~mm}$. of air and $92 \mathrm{~mm}$. of the combined gases. The first produced a deflexion beyond the limits of the scale. This corresponds to a value of $q$ of the order obtained in the first experiment of Table II. The other gave a value of $q$ equal to 042 .

These tables exhibit very great differences in the quantity of electricity produced by the explosion, far beyond the possible limits of experimental errors, and these are most 
produced by the Explosion of Hydrogen and Oxygen.

clearly marked, even in the cases where special care had been taken to reproduce the same conditions as far as possible. It was thought that this might be partly due to the explosion of the gas taking place to a large extent outside the field of force, for the mexploded gases were estimated to amount to between 5 and 10 per cent. of the gases originally present; and it will be seen, on referring to fig. 2 , that the spark which originated the explosions was entirely outside the yylinder. It also seemed possible that moisture caused by an explosion might affect the subsequent experiments. With the object of testing these points, a new apparatus was devised. The arrangements shown in fig. 1 were precisely the same as before, but the apparatus of fig. 2 was replaced by a brass cylinder $32 \cdot 2 \mathrm{~cm}$. Iong and $3 \cdot 75 \mathrm{~cm}$. internal diameter, ciosed by ebonite ends, to which the wire constituting, as before, the inner cylinder was directly fixed. The diameter of this wire was $3.18 \mathrm{~mm}$. The tubes and drying-bottles external to the cylinder were abolished, and instead new arrangements were substituted for exploding the gas well within the field of force and for drying the cylinder after explosion. The gas was exploded by means of a thin platinum wire placed within the cylinder and soldered to two brass rods which protruded through one of the ebonite ends of the cylinder, and which could be connected to the poles of a battery. The platinum wire could thus be heated to incandescence and the gas could be exploded. Practically all the gas which exploded with this arrangement lay within the field of force.

It was verified that when no explosion occurred the heating of the wire produced no electrical effect which conld be measured by the ballistic galvanometer.

The cylinder was dried after an explosion by warming it and passing dry air through it. This was done by means of two glass tubes fastened by air-tight joints to tho ebonite ends of the cylinder and communicating by means of pieces of pressure-tubing, which could be clipped, one with tubes containing calcium chloride and phosphorus pentoxide to dry the air as it entered, the other with a water pump. The latter tube was disconnected from the pump before making an experiment and joined to the apparatus of fig. 1, so that by its means the cylinder was filled with air or hydrogen and oxygen as might be required in the ordinary way. It was hoped in this way, by confining the explosion within the field of force, and by drying the cylinder after each experiment, to secure agreement between experiments made under 
the same conditions of pressure. This hope was not realized, as will be seen from the following table of results :-

'Table IV.

\begin{tabular}{|c|c|c|c|c|c|c|}
\hline$p$. & $p^{\prime}$. & $p^{\prime \prime}$. & $\pi$. & $\mathrm{V}$. & $\mathrm{Q}$. & $q$. \\
\hline 80 & 60 & 20 & 3 & 83 & $2 \cdot 3$ & $\cdot 038$ \\
84 & 63 & 21 & & 83 & -55 & $\cdot 0087$ \\
88 & 68 & 20 & & 83 & -305 & $\cdot 0045$ \\
\hline
\end{tabular}

The last observation is the mean of four experiments in each of which the field of force was identical and the amount of the mixed gases varied by only $1.5 \mathrm{~mm}$. The deflexions obtained were all small, giving values of $q$ ranging from $\cdot 0034$ to $\cdot 0064$. Except in the first experiment of the Table, the amount of air present was less than $1 \mathrm{~mm}$. It appeared, too, that a smaller percentage of the gas was exploded than with the previous apparatus. But some uncertainty arises from the difficulty of estimating the amount of water-vapour formed, since it diffused slowly through the pressure-tubing which led to the pentoxide of phosphorus.

With regard to the experiments generally, there are two quantities which it is sought to measure, the quantity of gas exploded and the amount of electricity formed. We consider that the experimental errors may be estimated at 5 per cent. in each case. The chief difficulty in measuring the former quantity was to make the proper allowance for the water-vapour formed by the explosion which is not absorbed immediately by the phosphorus pentoxide. It was observed that the pressure $p$ diminished by as much as $3 \mathrm{~mm}$. when the gases were left undisturbed for a considerable time. A neglect of this would involve an error of about 8 per cent. in the fall of pressure as calculated above. Accordingly, suitable corrections were applied to the pressures observed immediately after opening the pincheock $\mathrm{E}$, the effect of which would be that errors exceeding 4 per cent. could scarcely occur. This estimate, however, does not apply to Table IV.

In measuring the charge of electricity there was the possibility of a leak of electricity across the ebonite plug through which the wire passed, and of a misreading of the instrument. The former was obviated in the case of the electrometerobservations in the manner already described-in the case of 
produced by the Explosion of Hydrogen and Oxyyen. 47!

the galvanometer the discharge was instantaneous, and any leak sufficiently serious to affect the reading of the first throw would have given rise to a steady current which could not have escaped detection. There was, however, greater possibility of an error in reading the deflexion, especially when it consisted of but few divisions; but the observations in which there was reason to suspect a greater error than 5 per cent. have not been given in the tables.

In comparing the values of $q$, allowance must be made for the fact that in the first six experiments of Table III., and in those of which the mean is given after lable II., shields were placed round the tubes $G, G^{\prime}, L, L^{\prime}$, outside the cylinder and raised to the same potential with the cylinder, with the object of collecting a greater charge. The volume of the field of force was thus increased from 356 c.c. to 447 c.c., and consequently the values of $q$, had the shields not been present, would have been approximately four-fifths of the values actually given. But after making every allowance, some other cause must be sought for to explain the large discrepancies.

One fact seems to us to stand out very prominently, namely, the number of cases in which the electrical effects obtained in an experiment made when the contents of the cylinder were probably dry, bas very largely exceeded the effects given by experiments repeated very soon afterwards under conditions as far as possible the same. This may mean that the presence of moisture impedes the formation of ions very seriously. Thus, in the case of the electrometer, the first three experiments give values two to three times as great as were obtained afterwards. In Tables II. and III. the deflexion first obtained is largely in excess of those which immediately follow. In Table III. the ninth experiment and the two which succeed it were made at the same time, and the charge measured in the second experiment with the last. form of apparatus is notably less than that given by the first. On the other hand, prolonged attempts at drying, short of actually taking down the apparatus, failed to give more than a fraction of the maximum numbers obtained, and in some cases, notably when much air was present, greater values were found, when there was probably a considerable amount of moisture, than had been anticipated. Still, on the whole, we think that the presence of water-vapour checks the formation of ions, that when the cylinder and gases are perfectly dry the electricity generated per c.c. exploded at a pressure of $80 \mathrm{~mm}$. may be as large as 032 microcoulomb, but that when much moisture is present the amount may 
be reduced to as little as one fiftieth of this value. This result is got by dividing the largest value of $Q$ obtained, $11 * 4$, given by the first experiment with the low-resistance galvanometer, by 356 , the number of c.c. in the cylinder. It appears that an increase of electric force produces little or no effect, and that therefore, presumably, all the ions are collected when the outer cylinder is at 82 volts. This conclusion was arrived at from the experiments of Table $I$.

There is not sufficient evidence to show whether the presence of air produces an effect, but the experiments given in Table III., in which the quantity of air was varied, seem to point to the presence of air causing some increase in the ionisation. But, if this is so, it is far from proportional to the amount of air present. The matter is further complicated by the diminution in the completeness of the explosion when the amount of air is considerakle. This is shown in Table III.

The chief interest of these results lies, perhaps, in their bearing on the question whether the production of molecules of water-vapour from atoms of hydrogen and oxygen is accompanied by the formation of a comparable number of ions. The number of molecules of water-vapour formed is the number of molecules of hydrogen which enter into combination. Hence the number formed per c.c. for each millimetre fall of pressure of the mixed gases is $\frac{2}{3} \cdot \frac{\mathrm{N}}{760}=\frac{\mathrm{N}}{1140}$, where $\mathrm{N}$ is the number of molecules per c.c. at $760 \mathrm{~mm}$. pressure and $15^{\circ} \mathrm{C}$. The number of coulombs produced per c.c. is $\frac{q \times 10^{-6}}{v}$, where $v$ c.c. is the volume of the cylinder and $q$ has the same meaning as in the tables, or $\frac{3000 q}{v}$ electrostatic units. If then $e$ is the electrostatic charge on an ion, the number of pairs of ions produced bears to the number of molecules formed the ratio

$$
\frac{3000 q}{v e} \times \frac{1140}{\mathrm{~N}}=2.8 \times 10^{-4} \frac{y}{v}
$$

since $\mathrm{N} e=1.22 \times 10^{10}$ (J. S. Townsend, Phil. Trans. 1899). Taking the largest value of $q$ given by the experiments, $\cdot 144$, and $v=356$ c.c., the ratio becomes approximately $1 \cdot 1 \times 10^{-7}$. It would appear then that about ten million molecules of water-vapour are formed for every pair of ions produced, and that, too, when nearly 10 per cent. of the mixture is air. On the other hand, it is quite possible that i more suitable apparatus would produce greater electrical 
effects, as the large discrepancies seem to show that the limit has not been reached. Nevertheless, we think it highly improbable that these electrical effects are a direct result of chemical action, but believe rather that they are a secondary effect due to the enormous amount of heat set free by chemical union.

It can, in fact, be shown that the energy required for the formation of the ions is quite insignificant in comparison with that produced by the combination of hydrogen and oxygen. For the heat evolved when une gram of hydrogen enters into combination is 34,000 calories. In other words, when $v$ c.c. of hydrogen and oxygen are exploded at $p \mathrm{~mm}$. pressure, $34,000 \times \frac{2 p}{3 \times 760} \times v \rho \times 4.2$ joules are formed, where $\rho$ is the density of hydrogen at $15^{\circ} \mathrm{C}$. and $760 \mathrm{~mm}$. pressure. This equals $1.06 \times 10^{-2} \times p v$ joules. Again, to produce $Q$ coulombs of electricity of one sign in a gas by ionisation, $\frac{Q}{e^{\prime}}$ pairs of ions must be generated where $e^{\prime}$ is the charge on an ion measured in coulombs, and this will not require more than $5 \mathrm{Q}$ joules, since the energy necessary for the formation of each pair does not exceed $5 e^{\prime}$ joules (J. S. Townsend, Phil. Mag. Feb. 1901, p. 220). In our experiments $p$ was about $80 \mathrm{~mm} ., v 356$ c.c. and $Q$ not greater than $12 \times 10^{-6}$ coulombs. The heat set free was therefore approximately 300 joules, while the energy required for ionisation did not exceed $6 \times 10^{-5}$ joules, which is only one five millionth of the former quantity.

We wish to express our thanks to Professor Townsend for his valuable suggestions and criticisms.

XLVI. On the Open Organ-Pipe Problem in Two Dimensions. By Lord Rayleigh, O.M., F.R.S.*

TN the usual symmetrical organ-pipe of radius $R$, supposed 1 to be provided at the mouth with an infinite flange, we know that the correction ( $\alpha$ ) that must be added to the length in order that the open end may be treated as a loop, lies between $\frac{1}{4} \pi R$ and $8 R / 3 \pi$. The wave-length of vibration is here supposed to be very great, so that in the neighbourhood of the mouth the flow follows the electrical law. If we use this analogy and regard the walls of the pipe and the flange as non-conductors, the question is one of the resistance of the air-space, measured from a section well inside the pipe to an infinite distance beyond the mouth. And in spite

* Communicated by the Author.

Plit. Mag. S. 6. Vol. 8. No. 46. Oct. 1904. 